\title{
Corpo e tecnologia na sala de aula: estudos contemporâneos
}

Wilton Garcia

Pós-doutor em Multimeios pelo IA/Unicamp e doutor em Comunicação pela Escola de Comunicações e Artes da Universidade de São Paulo. É artista visual, pesquisador e professor com experiência na área de arte, comunicação e design sobre estudos contemporâneos. E-mail: wgarcia@usp.br

Resumo: Entre telefone celular, computador, internet e MP4, a cultura digital parece realinhar a ideia de corpo, sobretudo no âmbito atual da educação. Assim, é preciso repensar as situações emergentes dos desafios contemporâneos. O presente texto introduz uma reflexão conceitual e crítica, tomando estrategicamente aspectos socioculturais da comunicação que absorvem este contexto interdisciplinar no ambiente de ensino-aprendizagem. Imagem, experiência e subjetividade elencam-se como categorias discursivas, as quais são inscritas de modo diluído ao longo desta proposta. Portanto, os estudos contemporâneos efetivam uma abordagem teórico-metodológica, tentando observar como ocorrem os processos de atualização e inovação das linguagens no cotidiano da sala de aula.

Palavras-chave: corpo, cultura digital, educação, linguagem, tecnologia.
Abstract: Among cell phone equipment, computer, internet and MP4, digital culture seems realign the idea of body, especially in the current context of education. So we must rethink the emerging situations of contemporary challenges. This paper introduces a conceptual and critical thinking, taking some strategic sociocultural aspects of communication that absorb this interdisciplinary context in the teaching-learning environment. Image, experience and subjectivity list itself as discursive categories, which are included so diluted over the proposal. Thus, contemporary studies serve critically as the base for the theory-methodology approach, trying to see how the processes occur to update the language and innovation in the classroom everyday.

Keywords: body, digital culture, education, language, technology.

Na aula de português, a aluna de quinze anos (de calça justa, blusa curta, corpo jovem, pele morena e cabelo molhado) chega à sala atrasada, com fones no ouvido ligados a um pequeno aparelho de MP4 ${ }^{1}$. Eis um paradoxo, porque o ritmo sonoro é bastante acelerado em relação à aula. Ao mesmo tempo, a professora já está desenvolvendo uma dinâmica de redação com os demais alunos.

Ela, a adolescente, ouve uma música com o volume tão acima da média que os colegas conseguem escutar os ruídos estridentes que escapam dos fones - parece uma trilha de funk ou pagode. No embalo do chiado, o corpo discente começa a gargalhar. Agitação geral!

Recebido: 20.04.2009

1. Aparelho tecnológico que armazena a extensão de dados para arquivos digitais, utilizando o padrão de áudio mpeg-4. 
2. SOARES, Ismar de Oliveira. Quando o educador do ano é um educomunicador. Comunicação \& Educação, São Paulo: CCA-ECA-USP/Paulinas, ano XIII, n. 3, p. 47, set./ dez. 2008.

3. GARCIA, Wilton. Corpo, mídia e representação: estudos contemporâneos. São Paulo: Thomson Learning, 2005.
A referida cena descrita poderia atrapalhar a atividade escolar e causar grande transtorno no ambiente de ensino-aprendizagem planejado pela professora, que, no entanto, subverte o fato e traz essa breve interrupção a favor do desempenho educacional do alunado.

Aqui há uma passagem significativa que incita um momento único. É uma condicional específica de o professorado assumir o que acontece na sala de aula e não deixar que a algazarra da garotada tome conta do recinto.

Imediatamente, a professora decide contornar a situação e convida a aluna para falar com o grupo sobre o que está ouvindo. Para envolver o alunado, a docente inverte a posição ao implementar o acontecimento em uma rápida estratégia didático-pedagógica e relaciona a tecnologia do aparelho MP4 com a disciplina de português.

A descrição do evento anterior poderia não ter veracidade, seria uma ficção (um exemplo), se não fosse o registro pontual de um relato particular ocorrido em 2008 com uma professora, na periferia da cidade de São Paulo.

Para além do processo de educação formal, aquilo que não está regularmente planejado, por um lado, pode ser incorporado na sala de aula. $\mathrm{O}$ inusitado, a surpresa, pode mexer com o alunado. Por outro, os atores sociais da escola contemporânea necessitam pensar a prática educacional aplicada à realidade cotidiana na expectativa de refinar os propósitos. Algo que otimiza a vetorização crescente entre vida e escola.

Por isso, é importante observar que essas diretrizes fortalecem o desempenho de competências e habilidades no ambiente de ensino-aprendizagem. Trata-se de operar no sistema para se contaminar dele e, por esforço intelectual e crítico, contaminá-lo.

A fim de deixar mais claro o problema no ambiente de ensino-aprendizagem, junto com a diversificação de objetos tecnológicos, o corpo humano parece ser (re)significado e recorrente. A aparelhagem tecnológica, no exemplo supracitado, deve ser vista/lida como uma extensão do corpo dessa estudante. Logo, fica impossível proibir o uso de tecnologias quando se fala em uma cultura digital inclusiva.

Nesta vertente, interessa examinar a condição adaptativa do corpo e das tecnologias emergentes com a formação do sujeito, além do educar comprometido com os aspectos socioculturais de comunicação. Para Ismar de Oliveira Soares, a educomunicação é a garantia "de preparar o cidadão para assumir sua condição de agente comunicativo através do reconhecimento e do exercício compartilhado do direito universal à expressão"?.

Tenta-se, então, realizar uma espécie de texto-promessa, o qual projeta e constitui um recorte temático ao contexto antes descrito. Trata-se de investigar a articulação relacional entre corpo, educação e tecnologia junto aos estudos contemporâneos ${ }^{3}$.

Neste caso, os estudos contemporâneos são a base teórico-metodológica que constitui o desenvolvimento deste trabalho, a partir de duas categorias críticas: atualização e inovação. Ao descrever a dinâmica híbrida que relaciona corpo 
e cultura digital, busca-se nos estudos contemporâneos contextualizar, estrategicamente, uma abordagem teórico-metodológica para evidenciar as noções de atualização e inovação.

O contemporâneo (sub)verte e transgride os cânones do sistema dominante (mainstream), tendo em vista as diferentes manifestações testemunhadas, atualmente, em ações emergentes; ou seja, é algo recente, em discussão. Advertência: a contemporaneidade, aqui, deve ser observada através da linhagem teórica dos estudos culturais junto com as tecnologias emergentes.

A compreensão sobre as qualidades inventivas do contemporâneo requer (re) pensar seus efeitos de sentidos. O efeito torna-se um atrativo significativo para ressaltar impacto, surpresa, inovação e novidade. Esses feixes de efeitos equacionam maior distensão entre o objeto, sua representação e seu contexto, sobretudo na escritura expandida pela atualidade.

Esses estudos contemporâneos (do corpo, da cultura, da educação, da linguagem e das novas tecnologias) investigam fundamentos, conceitos, teorias, métodos, técnicas e críticas para realizar pressupostos e mediações de experiências, cujos aspectos sincréticos reforçam e revelam um registro aberto - em constante transformação.

E, com isso, pergunta-se: há um espaço de debate para esse tipo de enfrentamento sobre corpo e cultura digital no âmbito da educação hoje? O que a sala de aula (re)produz, atualmente, diante das novas ferramentas apresentadas pela cultura digital? Qual a influência dos instrumentos (hiper) midiáticos sobre a noção de corpo no cotidiano escolar? Se assim o for, quais as consequências disso nos diferentes contextos da escola pública e da escola privada?

Realizadas essas considerações preliminares, instauram-se, de modo sucinto, quatro tópicos que equacionam as dinâmicas reflexivas: A morada do corpo; Estudos contemporâneos; Efeitos da hipermídia; e Educação hoje. A distribuição desses tópicos, respectivamente, promove algumas amarrações pontuais sob o posicionamento conceitual e crítico deste trabalho, como contribuição de pressupostos para tratar da temática - corpo e cultura digital na educação contemporânea.

Destaca-se que são muitas provocações em um pequeno território reflexivo, cujos embates espalham e entrecruzam diferentes pontos de vista.

\section{A MORADA DO CORPO: UM CONCEITO}

\section{Meu corpo externa uma morada!}

Nos últimos dez anos, a realização anual de seminários, textos, exposições e publicações, que argumentam discussões acerca do corpo no contemporâneo, além da pesquisa com trabalhos científicos, no âmbito das ciências humanas, sobre o tema corpo $^{4}$ e as diversas representações, permitem a este pesquisador o desdobramento de uma possível teoria e política do corpo a partir da noção de transcorporalidade $^{5}$. Isto é, o trânsito do corpo, não o tráfego. Entre gestos e
4. COSTA, Jurandir Freire. $O$ vestígio e a aura: corpo e consumismo na moral do espetáculo. Rio de Janeiro: Garamond, 2004; VILLAÇA, Nizia. Edições do corpo: tecnociência, artes e moda. São Paulo: Estação das Letras, 2007.

5. GARCIA, op. cit. 
comunicação \& educação • Ano XV • número 3 • set/dez 2010

expressões corporais e faciais, postura e vestimenta, a aparência indica informação suficiente para comunicar.

Nesse trânsito, direciono a escrita sobre anotações conceituais e críticas de corpo - ponderando uma nova configuração mais ampla - para tentar atualizar algumas malhas (inter/trans) textuais, as quais emergem junto à demanda das tecnologias emergentes. Tanto na sala de aula quanto na sala de bate-papo no universo on-line ocorre uma constante manifestação da ação corporal entre diferentes planos: real, virtual e atual.

A cultura digital faz surgir novos enlaces perceptivos e cognitivos. As tecnologias (retro)alimentam a ideia de corpo. Discorre-se aqui de um corpo que absorve as (trans/de)formações e se compõe na linguagem - estratificada entre cultura e representação. Tais modificações somam as metamorfoses do corpo junto aos aparatos maquínicos.

O telefone celular na sala de aula, por exemplo, pode ser repensado como objeto de portabilidade contemporânea, na extensão do corpo - tal qual a caneta, o caderno ou a calculadora. Talvez a solução seja a(di)cioná-lo junto ao corpo que urge possibilidades criativas desse novo dispositivo comunicacional, capaz de ressignificar as tendências comportamentais contemporâneas. Logo, ele deixa de ser um problema.

É notório que esse contexto - de corpo e cultura digitais - sirva como fonte para despertar o interesse de intelectuais, pesquisadores, professores e profissionais aptos a investigar e acordar as mudanças da sociedade, bem como as representações na atualidade, ainda mais no âmbito da comunicação e da educação.

Vale a pena recorrer à experiência humana para observar a interpelação de procedimentos estéticos e técnicos instaurados pelo digital, que amplia a ideia de corpo. Isso reinscreve o modo como as pessoas pressupõem uma imagem corporal.

O corpo da aluna que entra na sala de aula com o fone de ouvido ligado no aparelho MP4 está acoplado à tecnologia como sistema. Neste sentido, a imagem corporal deve ser vista/lida diante da remodulação de signos digitais.

\section{ESTUDOS CONTEMPORÂNEOS - UMA PROPOSTA AOS PROFESSORES}

A forma de composição da informação contemporânea é bastante variada. E as múltiplas variantes de leituras e criação (de imagens, experiências, representações e subjetividades) são condições adaptativas fundamentais para o ambiente de ensino-aprendizagem, por exemplo, na educação e/ou no mercado profissional.

Ao pensar a informação desta maneira, evidenciam-se as tecnologias emergentes. A sociedade atual redireciona o interesse da ideologia para a tecnologia. Para o professorado, diria que é mais fácil conversar com o alunado sobre games, msn ou orkut do que discutir política. Evidente que continuam os fins 
ideológicos ao expor movimentos políticos, embora a força da cultura digital seja mais intensa diante do ideal de consumo.

Torna-se relevante investir nessa premissa para assegurar que hoje a informação é fragmentada, não linear e simultânea. Ela ocorre a partir de entrecruzamentos de manifestações que tornam mais complexa a experiência contemporânea. Então, isso deve ser visto/lido para além da configuração temporal, cronológica, que determina o agora. É muito mais que o tempo presente. Segundo Bhabha:

O trabalho fronteiriço da cultura exige um encontro com "o novo" que não seja parte do continuum de passado e presente. Ele cria uma ideia de novo como ato insurgente de tradução cultural. Essa arte não apenas retoma o passado como causa social ou precedente estético; ela renova o passado, refigurando-o como um "entrelugar" contingente, que inova e interrompe a atuação do presente. O "passado-presente" torna-se parte da necessidade, e não da nostalgia, de viver ${ }^{6}$.

Para este autor, que pensa a partir dos estudos culturais, o contemporâneo é parcial, provisório, efêmero, inacabado. Seria o que desloca, desliza, amplia e não se fixa. Trata-se de uma projeção conceitual e crítica capaz de relacionar a subjetividade do contemporâneo como espaço aberto - em constante transformação.

Portanto, propor uma transversalidade de olhares, os quais estabelecem aberturas dinâmicas com o atual. Tal transversalidade tenta lidar com parâmetros interdisciplinares que aglutinam corpo, cultura digital e educação, ao correlacionar as reverberações enunciativas do contemporâneo.

A interdisciplinaridade é o reconhecimento do signo emergente da diferença cultural produzida no movimento ambivalente entre a interpelação pedagógica e a performativa. Ela nunca é simplesmente a adição harmoniosa de conteúdos e contextos que aumentam a positividade de uma presença disciplinadora ou simbólica preestabelecida ${ }^{7}$.

Notadamente, este artigo surge na expectativa de expor um tecimento de ideias e saberes em uma perspectiva interdisciplinar, isto é, o que entrelaça posições distintas e, ao mesmo tempo, complementares. Enfim, observam-se os traços estratégicos que aproximam e, simultaneamente, distanciam articulações do interdisciplinar em variedades multi-trans-pluridisciplinares, para além de uma visão unilateral.

\section{EFEITOS DA HIPERMÍDIA - A ESCOLA TRANSFORMADA}

A cultura digital faz a gente repensar o uso das tecnologias.

Se os efeitos da hipermídia promovem transformações na sociedade hoje em dia, imagine na escola. Ao escrever sobre mutações no mundo contemporâneo, Adauto Novaes afirma: "Na história da humanidade, jamais se viveu um período tão radical de metamorfoses [...]. Criam-se, assim, diariamente, novas categorias para as coisas e para os fabulosos eventos a elas relacionados" .
6. BHABHA, Homi K. O local da cultura. Belo Horizonte: Editora UFMG, 1998. p. 27.

7. Ibid., p. 229.

8. NOVAES, Adauto (Org.). Mutações: ensaios sobre novas configurações no mundo. Rio de Janeiro: Agir; São Paulo: Edições Sesc-SP, 2008. p. 7 
Entre benefícios e malefícios, a façanha das tecnologias, agora, está abarcada pelo (des) envolvimento do mercado e da mídia. E a educação deve ponderar isso, pois ambos, mercado e mídia, procuram a(di)cionar novos territórios, que ativam o consumo, vendem produtos, incutem ideias. E para atualizar a informação, o futuro digital reconfigura imagens, sons e textos, cujos aparatos instrumentais e ferramentais não conseguem equacionar a própria produção do conhecimento.

A máxima da criação, em particular com a tecnologia digital, está na intenção de propiciar estrategicamente um diferencial criativo. Algo que expande, amplia e dá um "novo/outro" contexto - uma atmosfera subjetiva!

A escola reproduz estigmas que a sociedade projeta em mensagens sedutoras - para não dizer persuasivas - de mercado e mídia. A roupa da moda ou o estilo de se comportar com diferentes escolhas e atitudes são, por exemplo, uma resposta instantânea que (de)marca e assegura o diálogo do consumidor (também na comunidade escolar), que atende ao chamado de mercado e mídia. Nesse caso, mercado e mídia associam o consumo como fator recorrente na formação e constituição do sujeito contemporâneo.

Imagine o alunado tentando se reconhecer perante essas novas parafernálias digitais.

As transformações tecnológicas (avatares), eminentemente, ressaltam mudanças na vida cotidiana, inclusive na sala de aula, como sínteses que metamorfoseiam a abordagem relacional humano-tecnológica. A passagem da modificação, então, (re)constitui um outro modo de ser/estar dos objetos e das pessoas. Especialmente, aqui, essas transformações existem a partir do momento em que se observa o uso do computador, de forma intensa, como recurso ferramental relevante no desenvolvimento das habilidades humanas no ambiente de ensino-aprendizagem.

\section{EDUCAÇÃO HOJE: DESAFIOS}

Fica reafirmado, portanto, que a educação indiscutivelmente acompanha os avanços e/ou os retrocessos das tecnologias emergentes e as (trans/de)formações do corpo, para além dos fatores de engenharia maquínica, computacional e humana. As variáveis compreendidas pela cultura digital aglutinam uma série de novidades. Telefone celular, computador, internet e/ou aparelho MP4 são objetos tecnológicos que surgem, constantemente, em uma sala de aula proliferando desafios.

Então, como lidar com essas cenas? Não é possível fechar os olhos para a cultura digital. É preciso trabalhar a vivência tecnológica no cenário escolar, de acordo com o exemplo na introdução deste texto. Sinto-me, como professor e pesquisador, instigado a aprofundar no ambiente de ensino-aprendizagem acerca do corpo e da cultura digital - novas mídias, games, interatividade, novas redes e linguagens. 
Com efeito, comunicar prevalece de (in) $\operatorname{certezas}^{9}$ e requer mais que emissor, receptor, mensagem, código e canal. Reagrupa-se entre a disposição da interatividade. Um procedimento comunicacional suscita resultados.

Também, novos/outros movimentos dinâmicos permeiam a relação professor/aluno com o ambiente de ensino-aprendizagem. Ao transversalizar tal composição, agenciam-se, negociam-se os (re)posicionamentos, que não podem mais constituir hierarquias. Afinal, o objetivo é a participação colaborativa em que todos/as contribuem. Professor (educador, facilitador, mediador) e aluno tornam-se usuários-interatores do sistema computacional. Ou seja, a expectativa de desenvolvimento dos aspectos socioculturais de comunicação promove, paulatinamente, o acesso à educação atualizada - via rede de informação digital.

Para Nestor Canclini, "a escola ensina posições corretas para ler livros, a mídia, como colocar-nos para sermos espectadores ou seduzirmos, e o corpo para inexistir quando se fala em conectar-se com as redes virtuais invisíveis" ${ }^{10}$. Portanto, seria relevante a ampliação de estudos contemporâneos vetorizados em investigações exploratórias que (re)dimensionem a flexibilidade entre corpo e tecnologia no enfoque educacional. Nessa (in)formação, toma-se a sistematização de experiências que potencializam a discussão corpo/máquina para exibir o caráter multifacetado da hipermídia.

\section{CONSIDERAÇÕES (SOBRE A ESCOLA CONTEMPORÂNEA)}

No decorrer deste artigo, foi realizada uma ação exploratória de (re)aproveitamento de meios comunicacionais hipermidiáticos na vida escolar. Talvez essas impressões possam ser traduzidas mediante as abundantes inovações de corpo e cultura digital na educação contemporânea. Essa última parece se impregnar nas diversas redes de coordenadas elaboradas pelas trocas de experiências influenciadas com o compartilhamento de ideias.

Como desafio didático-pedagógico, cabe ao professorado trabalhar a diversidade espontânea do alunado em sala de aula. É criar alternativas necessárias para garantir o desempenho educacional. $\mathrm{O}$ enfrentamento pode ter controvérsias, no entanto, fica evidente o papel do docente ao posicionar-se perante o mundo e, com isso, servir de base referencial para o desenvolvimento de valores humanos na comunidade escolar. A responsabilidade do professorado perante o alunado, hoje, deve ser flexível e mediadora de agenciamentos/ negociações entre a realidade social do grupo e a emergência de temas como a cultura digital.

Pensar as questões aqui abordadas faz valer uma linha de investigação sincrética que (re)inscreve o deslocamento e a flexibilidade da percepção sobre o alunado e o professorado para atualizar a experiência em sala de aula. Cada sujeito deve tomar seu posicionamento de mundo: um ponto de vista a ser defendido. Seria a singularidade da escolha que enuncia a resultante.

Aqui, (des) caminhos entrecruzam efeitos!
9. MORIN, Edgard. Os sete saberes necessários à educação do futuro. São Paulo: Unesco/Cortez, 2000.

10. CANCLINI, Néstor Garcia. Leitores, espectadores e internautas. São Paulo: Iluminuras, 2008. p. 42. 
comunicação \& educação • Ano XV • número 3 • set/dez 2010

\section{REFERÊNCIAS BIBLIOGRÁFICAS}

BHABHA, Homi K. O local da cultura. Tradução de Myriam Ávila, Eliana L. L. Reis e Gláucia R. Gonçalves. Belo Horizonte: Editora UFMG, 1998.

CANCLINI, Néstor Garcia. Leitores, espectadores e internautas. Tradução de Ana Goldberger. São Paulo: Iluminuras, 2008.

COSTA, Jurandir Freire. O vestígio e a aura: corpo e consumismo na moral do espetáculo. Rio de Janeiro: Garamond, 2004.

GARCIA, Wilton. Corpo, mídia e representação: estudos contemporâneos. São Paulo: Thomson Learning, 2005.

MORIN, Edgard. Os sete saberes necessários à educação do futuro. Tradução de Catarina Eleonora F. da Silva e Jeane Sawaya. São Paulo: Unesco/Cortez, 2000.

NOVAES, Adauto (Org.). Mutações: ensaios sobre novas configurações no mundo. Rio de Janeiro: Agir; São Paulo: Edições Sesc-SP, 2008.

SOARES, Ismar de Oliveira. Quando o educador do ano é um educomunicador. Revista Comunicação \& Educação, São Paulo: CCA-ECA-USP/Paulinas, ano XIII, n. 3, p. 39-52, set./dez. 2008.

VILLAÇA, Nizia. Edições do corpo: tecnociência, artes e moda. São Paulo: Estação das Letras, 2007. 